\title{
Myocardial bioenergetic abnormalities in experimental uremia
}

This article was published in the following Dove Press journal: International Journal of Nephrology and Renovascular Disease 24 May 2016

Number of times this article has been viewed

\author{
Alistair MS Chesser' \\ Steven M Harwood ${ }^{2}$ \\ Martin J Raftery' \\ Muhammad M Yaqoob ${ }^{1,2}$ \\ 'Department of Nephrology, Barts \\ Health NHS Trust, Royal London \\ Hospital, ${ }^{2}$ Translational Medicine \\ and Therapeutics, William Harvey \\ Research Institute, John Vane Science \\ Centre, Queen Mary University of \\ London, London, UK
}

Purpose: Cardiac bioenergetics are known to be abnormal in experimental uremia as exemplified by a reduced phosphocreatine (PCr)/adenosine triphosphate (ATP) ratio. However, the progression of these bioenergetic changes during the development of uremia still requires further study and was therefore investigated at baseline, 4 weeks and 8 weeks after partial nephrectomy (PNx).

Methods: A two-stage PNx uremia model in male Wistar rats was used to explore in vivo cardiac and skeletal muscles' bioenergetic changes over time. High-energy phosphate nucleotides were determined by phosphorus-31 nuclear magnetic resonance ( $\left.{ }^{31} \mathrm{P}-\mathrm{NMR}\right)$ and capillary zone electrophoresis.

Results: ${ }^{31} \mathrm{P}-\mathrm{NMR}$ spectroscopy revealed lower PCr/ATP ratios in PNx hearts compared to sham $(\mathrm{SH})$-operated animals 4 weeks after $\mathrm{PNx}$ (median values given $\pm \mathrm{SD}, 0.64 \pm 0.16 \mathrm{PNx}$, $1.13 \pm 0.31 \mathrm{SH}, P<0.02)$. However, 8 weeks after $\mathrm{PNx}$, the same ratio was more comparable between the two groups $(0.84 \pm 0.15 \mathrm{PNx}, 1.04 \pm 0.44 \mathrm{SH}, P=$ not significant $)$, suggestive of an adaptive mechanism. When 8 -week hearts were prestressed with dobutamine, the PCr/ATP ratio was again lower in the $\mathrm{PNx}$ group $(1.08 \pm 0.36 \mathrm{PNx}, 1.55 \pm 0.38 \mathrm{SH}, P<0.02)$, indicating a reduced energy reserve during the progression of uremic heart disease. ${ }^{31} \mathrm{P}-\mathrm{NMR}$ data were confirmed by capillary zone electrophoresis, and the changes in myocardial bioenergetics were replicated in the skeletal muscle.

Conclusion: This study provides evidence of the changes that occur in myocardial energetics in experimental uremia and highlights how skeletal muscle bioenergetics mirror those found in the cardiac tissue and so might potentially serve as a practical surrogate tissue during clinical cardiac NMR investigations.

Keywords: PCr/ATP ratio, ${ }^{31} \mathrm{P}-\mathrm{NMR}$, uremic cardiomyopathy

\section{Introduction}

Ischemic heart disease, hypertension, and anemia are common in patients with chronic kidney disease (CKD), but there is evidence that a number of other important factors contribute to the clinical syndrome that has been termed uremic cardiomyopathy. The changes seen in the uremic heart have not been shown to be specific to uremia, and it is likely that uremic cardiomyopathy is multifactorial and derived from a combination of features present in the uremic patient. The critical importance of bioenergetics during the development of uremic cardiomyopathies and of the signaling pathways involved has been highlighted, including the role of $\mathrm{mTOR}^{1}$ and insulin resistance via Akt. ${ }^{2}$ However, while changing cardiac bioenergetics have been studied in many different pathologies, such as left ventricular hypertrophy (LVH), obesity, diabetes,
Correspondence: Steven M Harwood Translational Medicine and Therapeutics, William Harvey Research Institute, John Vane Science Centre, Queen Mary University of London, Charterhouse Square, London ECIM 6BQ, UK $\mathrm{Tel}+442078822122$

Fax +44 2078828252

Email s.m.harwood@qmul.ac.uk

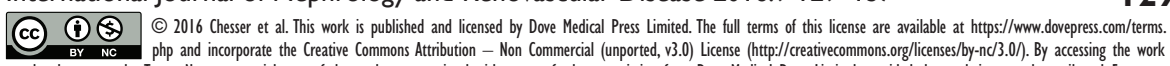
you hereby accept the Terms. Non-commercial uses of the work are permitted without any further permission from Dove Medical Press Limited, provided the work is properly attributed. For

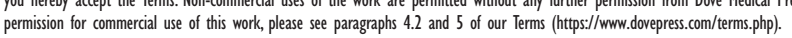


heart failure, and myocardial ischemia, ${ }^{3-7}$ the progressive bioenergetic changes found in the uremic heart have been largely overlooked.

It is an established practice when assessing myocardial bioenergetics to calculate the phosphocreatine (PCr)/ adenosine triphosphate (ATP) ratio. This is because ATP production within the myocardium is produced largely from intramitochondrial oxidative phosphorylation. This in turn is then transported to the sites of energy utilization, particularly the myofibrils. This is enabled by the generation of PCr that diffuses to the myofibrils where ATP is regenerated. Increases in energy demand tend, therefore, to result in a decreased PCr/ATP ratio rather than a fall in ATP. Thus, the PCr/ATP ratio represents a measure of instantaneous cardiac energetic state. ${ }^{3}$

Clinical studies of LVH using phosphorus-31 nuclear magnetic resonance $\left({ }^{31} \mathrm{P}-\mathrm{NMR}\right)$ have tended to suffer from small patient numbers and have shown conflicting results. ${ }^{8,9}$ Both Conway et $\mathrm{al}^{10}$ and Neubauer et $\mathrm{al}^{11}$ while studying patients with aortic stenosis and investigating patients with aortic incompetence, respectively, found that any reduction in the $\mathrm{PCr} / \mathrm{ATP}$ ratio was related to the degree of heart failure. However, a study of patients with mitral regurgitation found significant reductions in the $\mathrm{PCr} / \mathrm{ATP}$ ratio that correlated with both the degree of heart failure and LVH. ${ }^{12}$ Lamb et $\mathrm{al}^{13}$ found a reduced PCr/ATP ratio in eleven hypertensive patients with a strong association between ratios and the degree of diastolic dysfunction. More recent work using a higher magnetic field ( $3 \mathrm{~T}$ instead of $1.5 \mathrm{~T})^{7}$ and a larger patient population revealed that the $\mathrm{PCr} / \mathrm{ATP}$ ratio is greatly reduced in patients with hypertrophic cardiomyopathy $(n=26)$ compared to control subjects $(\mathrm{n}=37, P<0.0001)$. In contrast to these results, studies of elite athletes with "physiological" LVH have shown no reduction in the PCr/ATP ratio compared to that of control subjects. ${ }^{14}$

There are only a few cardiac bioenergetics studies available about patients with CKD. Tagami et al ${ }^{15}$ studied 14 CKD patients treated with maintenance dialysis (hemodialysis or continuous ambulatory peritoneal dialysis) and found a decreased cardiac PCr/ATP ratio, particularly in patients with a history of heart failure. Perseghin et $\mathrm{al}^{16}$ compared the left ventricle PCr/ATP ratio in many different patient groups and found a significant reduction when comparing uremic patients $(n=10)$ with control subjects $(n=13)$. More recent work by Patel et $\mathrm{al}^{17}$ demonstrated that patients with CKD had lower PCr/ATP ratios than hypertensive patients with and without LVH. This observation confirms the much earlier findings of Raine et $\mathrm{al}^{18}$ who found that the uremic rat (partial nephrectomy [PNx]) had significantly lower PCr/ATP ratios in the uremic group compared to sham (SH)-operated control animals. This reduction in the PCr/ATP ratio was accompanied by reduced contractile indices in the functional assessment of the uremic hearts. However, much of this work was generated using an ex vivo Langendorff heart preparation that limits its clinical significance.

Most of the clinical and experimental studies conducted so far have been cross-sectional in nature, which has ensured that the mechanism by which uremia induces cardiac energetic changes over time remains largely unknown. The longitudinal study presented here attempts to address this lack of knowledge by following the bioenergetic changes that occur in an experimental rat model of uremia. The hearts were studied in vivo using NMR spectroscopy to investigate the time course of changes in the PCr/ATP ratio after PNx. The relationship of the bioenergetic parameters to the degree of uremia, hemoglobin status, and blood pressure were all studied. Cardiac and skeletal muscles were assessed with the aim of identifying if parallel changes occurred in both tissues. In addition, confirmation of our NMR findings was sought by using a distinct methodology (capillary zone electrophoresis [CZE]) to determine $\mathrm{PCr}$ and ATP concentrations.

\section{Methods \\ PNx model of chronic uremia in the rat}

All procedures were performed on male Wistar rats after obtaining ethical permission from the home office (UK) (project license number PPL/5014). Care of the rats was carried out in accordance with the Animals (Scientific Procedures) Act 1986. The animals (150-200 g) were purchased from Charles River Ltd (Margate, Kent, UK). A 5/6th PNx model was used that has long been established in our laboratory. ${ }^{19}$ The two stages of the procedure were performed 7 days apart.

\section{Anesthesia for PNx}

Initially, animals were given an intramuscular injection of $0.16 \mathrm{~mL}$ Hypnorm (fentanyl citrate $0.315 \mathrm{mg} / \mathrm{mL}$ and fluanisone $10 \mathrm{mg} / \mathrm{mL}$ from Janssen-Cilag Ltd, Saunderton, High Wycombe, Bucks, UK) into the hind leg. Subsequently, an intraperitoneal (ip) injection of $0.1 \mathrm{~mL}$ diazepam (Phoenix Pharmaceuticals Ltd, Gloucester, UK) was given. This combination induced deep anesthesia lasting 40-50 minutes, sufficient to cover the surgery period.

\section{Blood pressure measurement}

Blood pressure was measured by the direct cannulation of the femoral artery. Gaseous anesthesia was administered to the 
animals in the form of nitrous oxide $(1 \mathrm{~L} / \mathrm{min})$ and oxygen $(1 \mathrm{~L} / \mathrm{min})$ with gaseous halothane $(2 \%)$ until the animal was unconscious. Throughout surgery, the same concentrations of nitrous oxide and oxygen were given and the concentration of halothane was varied between $1 \%$ and $2 \%$ in order to maintain deep anesthesia. The animals were allowed to recover from surgery, and blood pressure was measured in the conscious unrestrained rat at least 24 hours and no later than 4 days following line insertion. The blood pressure was measured continuously for 10 minutes for all analyses, but only the final 5 minutes of recording was used. The mean blood pressures were calculated, as the damping effect of the tubing affected the values of peak systolic and diastolic pressures without affecting the mean pressure.

\section{Cardiac NMR studies}

Following blood pressure measurement, the rat was given an ip injection of sodium thiopentone $30 \mathrm{mg} / \mathrm{kg}$ body weight. A $1 \mathrm{~cm}$ midline incision was made in the front of the neck. The trachea was identified within the strap muscles, and a silk tie was passed behind it. Using a handheld cutting diathermy, a hole was made in the trachea a few millimeters across. The tracheostomy tube was inserted into the trachea through this hole, tied in position, and connected to a ventilator via a length of Portex tubing. The ventilator was set at a ventilator frequency of 58/minute, with a variable stroke volume. A sample of arterial blood was taken via the femoral arterial line and analyzed in a blood gas analyzer. The stroke volume of the ventilator was adjusted so that the $\mathrm{pH}$ of the blood was between 7.3 and 7.5. Supplementary oxygen was given as required according to blood gas measurement so that the animal was at no stage hypoxic.

\section{Preparation of the heart for NMR}

The method was based on that of Beech et $\mathrm{al}^{20}$ and has been previously described.

\section{Preparation of skeletal muscle for NMR}

A skin flap was retracted from the adductor muscles of one thigh. The $8 \mathrm{~mm}$ surface coil was placed over this muscle, separated from it by a layer of plastic film. The animal was placed in the center of the magnet. Spectroscopy methods for both cardiac and skeletal muscles were identical (see the “31P-NMR spectroscopy measurements” section).

\section{${ }^{31} \mathrm{P}-\mathrm{NMR}$ spectroscopy measurements}

The animal was placed in the bore of an Oxford Instruments 4.7 T horizontal bore superconducting magnet (Oxford Instruments, Abingdon, UK) interfaced with a SISCO 200 imaging spectrometer (Spectroscopy Imaging Systems Co., Varian Medical Systems UK Ltd, Crawley, UK). The surface coil was tuned to $81 \mathrm{MHz}$, and the magnetic field was optimized by shimming on the ${ }^{1} \mathrm{H}$ (water) signal from tissue. ${ }^{31} \mathrm{P}-\mathrm{NMR}$ spectra were then recorded at $81 \mathrm{MHz}$. A $50 \mu$ s nonselective pulse was applied with a pulse interval of 1.96 seconds. Spectra were acquired by signal-averaging 512 pulse repetitions, leading to a total acquisition time of 16 minutes. Acquired free induction decays were exponentially multiplied with a line broadening of $20 \mathrm{~Hz}$. The data were then Fourier transformed, and first-order phase correction was carried out manually.

\section{Preparation of hearts for CZE}

The hearts used for this study originated from two different sets of animals: those with unstressed and those with stressed hearts. Unstressed hearts were obtained from rats at 4 weeks and 8 weeks following PNx. The heart was exposed and freeze clamped using steel tongs precooled in liquid nitrogen. Stressed hearts 8 weeks following $\mathrm{PNx}$ were obtained from animals given intravenous dobutamine as an infusion (15 $\mu \mathrm{g} \cdot \mathrm{kg}^{-1} \cdot \mathrm{min}^{-1}$ ) for 20 minutes prior to freeze clamping. A blood gas sample was taken to ensure that $\mathrm{pH}$ and $\mathrm{pO}_{2}$ remained within the desired range. Blood was reserved for hemoglobin and creatinine measurement from both stressed and unstressed hearts.

\section{Extraction of nucleotides from cardiac tissue for CZE}

Approximately $100 \mathrm{mg}$ of heart tissue was ground with a mortar and pestle in liquid nitrogen and accurately weighed and extracted in ice-cold $9 \%$ perchloric acid $(1 \mathrm{~mL}$ perchloric acid solution per $100 \mathrm{mg}$ tissue). ${ }^{21}$ The sample was vigorously shaken, and the homogenate was centrifuged at $16,000 \times g$ for 3 minutes at $4^{\circ} \mathrm{C}$. The supernatant was removed and neutralized using potassium hydroxide $(5 \mathrm{~mol} / \mathrm{L})$. The neutralized supernatant was centrifuged to precipitate all the formed potassium perchlorate, and the remaining solution was then stored at $-80^{\circ} \mathrm{C}$. Before analysis by $\mathrm{CZE},{ }^{21}$ the sample was recentrifuged and any further precipitate excluded. At all stages, the volumes of samples were carefully measured and recorded. In addition, for each heart, $\sim 100 \mathrm{mg}$ of freezeclamped myocardium was dried using vacuum centrifugation to allow calculation of wet weight to dry weight ratios.

\section{CZE}

All determinations were performed on a Thermo Separation Products [TSP] 2000 Capillary Electrophoresis instrument (TSP, Stone, UK). Data collecting and handling were carried out using dedicated software (Spectacle; TSP). The 
electrophoretic analyses were performed using a fused silica capillary ( $35 \mathrm{~cm}$ from injector to detector, $42 \mathrm{~cm}$ total length, and $50 \mu \mathrm{m}$ internal diameter) as previously described. ${ }^{22}$ Samples were injected in hydrodynamic mode for 3 seconds. The voltage applied was $17.5 \mathrm{kV}$, and ultraviolet (UV) detection was performed at $254 \mathrm{~nm}$ for adenine nucleotides or $200 \mathrm{~nm}$ for PCr. The capillary was thermostatically maintained at $25^{\circ} \mathrm{C}$. The separation buffer used in all experiments was sodium tetraborate $(20 \mathrm{mM})$ and ethylenediaminetetraacetic acid (1 mM), adjusted to $\mathrm{pH}$ 9.2. The spatial area of each peak was calculated by integrating the area of the migration time. For each standard, the area under the curve was plotted against the concentration injected and calibration curves were constructed. From the spatial area of each peak on the electropherogram of each heart sample extract, the concentration of each substance was determined from the calibration curves.

\section{Statistics}

Differences between groups were compared by using either a two-tailed parametric test (unpaired Student's $t$-test) or a nonparametric test (two-tailed Mann-Whitney test) where appropriate (GraphPad Prism 5.04; GraphPad Software, Inc., La Jolla, CA, USA).

\section{Results}

\section{Unstressed hearts}

\section{Four-week heart NMR study}

Four weeks after completion of surgery in $\mathrm{PNx}$ and $\mathrm{SH}-$ operated animals, seven control and six PNx animals yielded spectra suitable for analysis. Baseline data for the animals included in the analysis are shown in Table 1. PNx rats were significantly anemic and hypertensive, with significantly raised serum creatinine concentrations. There was no significant difference in the final weights of the animals. Figure $1 \mathrm{~A}$ shows the PCr/ATP ratio calculated for each group and demonstrates a significant difference in the $\mathrm{PCr} / \mathrm{ATP}$ ratio between control and uremic animals.

Table I Four-week heart NMR study

\begin{tabular}{llll}
\hline & Control & Uremic & $P$ \\
\hline Number of animals & 7 & 6 & \\
Days following PNx/sham operation & $29.3 \pm 4.9$ & $30.0 \pm 4.1$ & $\mathrm{NS}$ \\
Weight $(\mathrm{g})$ & $350.0 \pm 54.0$ & $318.7 \pm 82.5$ & $\mathrm{NS}$ \\
Mean arterial blood pressure $(\mathrm{mmHg})$ & $129.7 \pm 11.1$ & $150.1 \pm 20.6$ & 0.02 \\
Hemoglobin $(\mathrm{g} / \mathrm{dL})$ & $11.5 \pm 1.9$ & $8.7 \pm 1.2$ & 0.04 \\
Urea $(\mathrm{mmol} / \mathrm{L})$ & $6.24 \pm 0.88$ & $16.35 \pm 0.92$ & $<0.01$ \\
Creatinine $(\mu \mathrm{mol} / \mathrm{L})$ & $50.6 \pm 15.7$ & $175 \pm 81.3$ & $<0.01$ \\
\hline
\end{tabular}

Notes: Baseline data for animals studied by heart NMR 4 weeks post-PNx or sham operation. Values given are mean $\pm S D$, and statistical analysis was performed by unpaired Student's $t$-test.

Abbreviations: NMR, nuclear magnetic resonance; PNx, partial nephrectomy; NS, not significant.
Table 2 Eight-week heart NMR study

\begin{tabular}{llll}
\hline & Control & Uremic & $P$ \\
\hline Number of animals & 7 & 5 & \\
Days following PNx/sham operation & $60.4 \pm 5.7$ & $61.8 \pm 1.8$ & $\mathrm{NS}$ \\
Weight $(\mathrm{g})$ & $370.0 \pm 40.6$ & $367.2 \pm 21.9$ & $\mathrm{NS}$ \\
Mean arterial blood pressure $(\mathrm{mmHg})$ & $124.7 \pm 5.6$ & $149.2 \pm 8.9$ & $<0.01$ \\
Hemoglobin $(\mathrm{g} / \mathrm{dL})$ & $12.9 \pm 3.0$ & $9.7 \pm 1.8$ & $<0.01$ \\
Urea $(\mathrm{mmol} / \mathrm{L})$ & $7.06 \pm 0.97$ & $15.03 \pm 2.15$ & $<0.01$ \\
Creatinine $(\mu \mathrm{mol} / \mathrm{L})$ & $46.8 \pm 8.1$ & $91.5 \pm 23.5$ & $<0.01$ \\
\hline
\end{tabular}

Notes: Baseline data for animals studied by heart NMR 8 weeks post-PNx. Values given are mean $\pm S D$, and statistical analysis was performed by unpaired Student's t-test.

Abbreviations: NMR, nuclear magnetic resonance; PNx, partial nephrectomy; NS, not significant.

\section{Eight-week heart NMR study}

Eight weeks from completion of surgery, seven control and five PNx animals yielded spectra suitable for analysis. Summaries of the animal weights, blood pressures, and blood parameters are shown in Table 2. Figure 1B shows the $\mathrm{PCr}$ / ATP ratio of each group. Unlike the 4-week data here, there was no significant difference in PCr/ATP ratios between control and uremic hearts ( $P=$ not significant). In addition, there was no significant correlation found between PCr/ATP ratio and mean arterial blood pressure or with serum urea or creatinine concentrations.

\section{Four-week skeletal muscle NMR study}

Eight control and seven PNx animals yielded spectra suitable for analysis. Reassuringly, intracellular $\mathrm{pH}$ was not significantly different as measured by NMR when comparing control and PNx groups (Table 3), as it could not be measured reliably in our in vivo cardiac study. PCr/ATP ratios were significantly lower in the skeletal muscle of the uremic group compared to that of the control group (Figure 1C), independent of intracellular $\mathrm{pH}$.

\section{Eight-week skeletal muscle NMR study}

Five control and eight uremic animals yielded spectra suitable for analysis (Table 4). There was no significant difference

Table 3 Four-week skeletal muscle NMR study

\begin{tabular}{llll}
\hline & Control & Uremic & $P$ \\
\hline Number of animals & 8 & 7 & \\
Animal weight $(\mathrm{g})$ & $335 \pm 48$ & $299 \pm 45$ & $\mathrm{NS}$ \\
Mean arterial blood pressure $(\mathrm{mmHg})$ & $\mathrm{I} 10.2 \pm 8.1$ & $139.8 \pm 10.0$ & $<0.0 \mathrm{I}$ \\
Hemoglobin $(\mathrm{g} / \mathrm{dL})$ & $12.6 \pm 0.4$ & $8.9 \pm 1.1$ & $<0.0 \mathrm{I}$ \\
Creatinine $(\mu \mathrm{mol} / \mathrm{L})$ & $50.6 \pm 15.7$ & $175 \pm 81.3$ & $<0.0 \mathrm{I}$ \\
Intracellular $\mathrm{pH}$ & $7.12 \pm 0.30$ & $7.17 \pm 0.10$ & $\mathrm{NS}$ \\
\hline
\end{tabular}

Notes: Four-week baseline data for the NMR study using rat skeletal muscle. Values given are mean $\pm S D$, and statistical analysis was performed by unpaired Student's $t$-test.

Abbreviations: NMR, nuclear magnetic resonance; NS, not significant. 

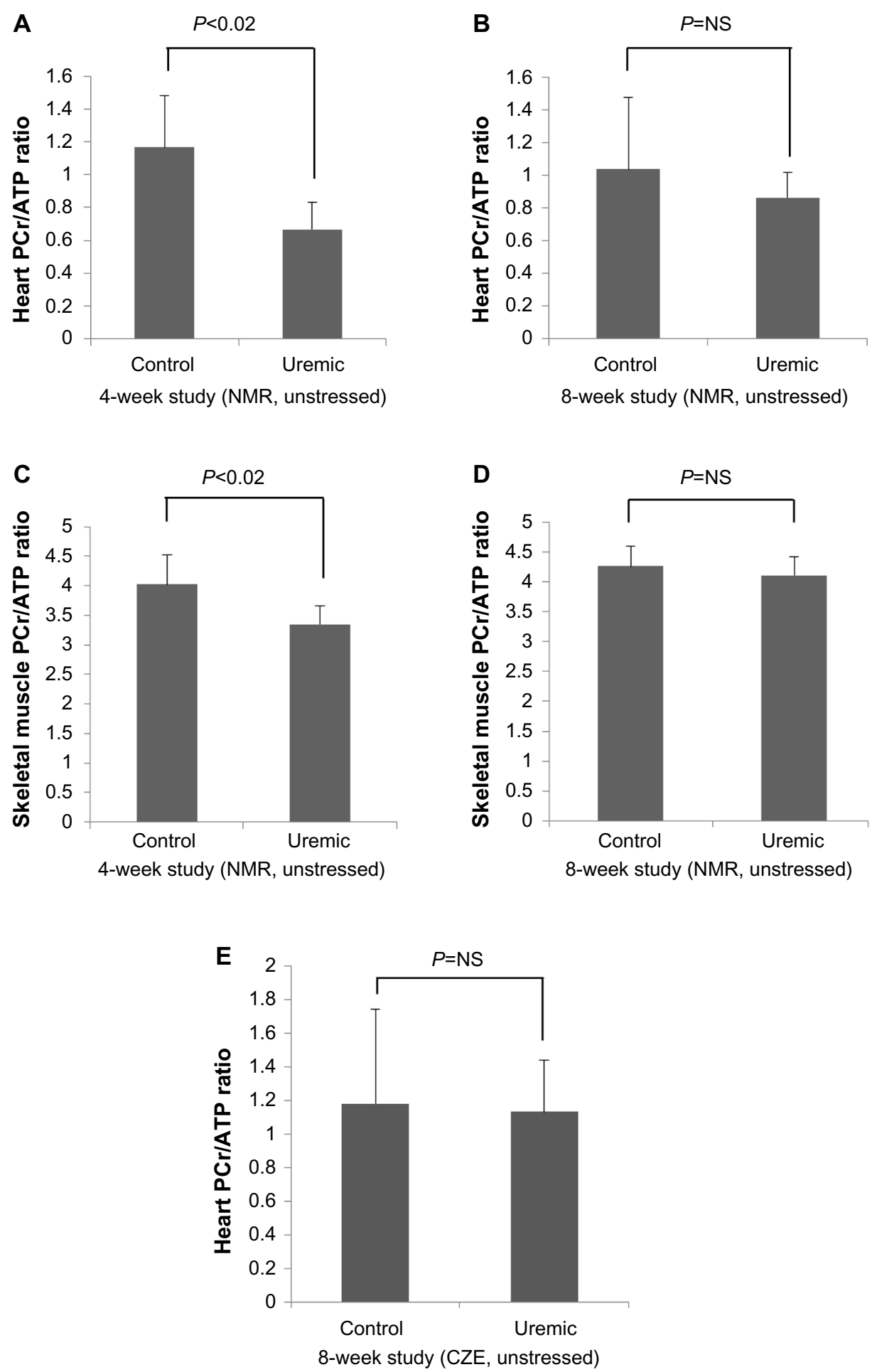

Figure I PCr/ATP ratios in 4 weeks and 8 weeks post-PNx in unstressed rats.

Notes: After 4 weeks of uremia, NMR revealed that PCr/ATP ratios were significantly reduced in both cardiac and skeletal muscles (A and C). At 8 weeks, no significant difference in the ratio was seen (B and D). CZE confirmed the cardiac NMR findings at 8 weeks (E). Two-tailed Mann-Whitney analysis with median values \pm SD is presented.

Abbreviations: PCr, phosphocreatine; ATP, adenosine triphosphate; PNx, partial nephrectomy; NMR, nuclear magnetic resonance; CZE, capillary zone electrophoresis; NS, not significant.

in PCr/ATP ratios (Figure 1D, two-tailed Mann-Whitney test) when comparing control to PNx animals, similar to the findings shown in the myocardial studies at this time point (Figure 1B, two-tailed Mann-Whitney test).

\section{Eight-week CZE study}

Eight pairs of hearts were suitable for study. CZE measurements showed no significant differences in the concentrations of PCr, ATP, adenosine diphosphate, or adenosine 
Table 4 Eight-week skeletal muscle NMR study

\begin{tabular}{llll}
\hline & Control & Uremic & $P$ \\
\hline Number of animals & 5 & 8 & \\
Animal weight $(\mathrm{g})$ & $369 \pm 35$ & $374 \pm 20.5$ & $\mathrm{NS}$ \\
Mean arterial blood pressure $(\mathrm{mmHg})$ & $118.1 \pm 10.2$ & $143.3 \pm 12.7$ & 0.03 \\
Hemoglobin $(\mathrm{g} / \mathrm{dL})$ & $12.4 \pm 0.2$ & $8.8 \pm 2.4$ & $<0.01$ \\
Creatinine $(\mu \mathrm{mol} / \mathrm{L})$ & $43.7 \pm 2.1$ & $102.0 \pm 27.3$ & $<0.01$ \\
Intracellular $\mathrm{pH}$ & $7.15 \pm 0.13$ & $7.19 \pm 0.13$ & $\mathrm{NS}$ \\
\hline
\end{tabular}

Notes: Eight-week baseline data for the NMR study using rat skeletal muscle. Values given are mean $\pm S D$, and statistical analysis was performed by unpaired Student's $t$-test.

Abbreviations: NMR, nuclear magnetic resonance; NS, not significant.

monophosphate (Table 5) when comparing control to uremic hearts. In addition, PCr/ATP ratios were not significantly different between control and uremic hearts (Figure 1E, two-tailed Mann-Whitney test).

\section{Stressed hearts (dobutamine treated)}

Eight-week stressed heart NMR study

Five pairs of animals yielded spectra suitable for analysis (Table 6). In baseline conditions, there was no significant difference between the two groups' PCr/ATP ratios. When the spectra were reacquired during the infusion of intravenous dobutamine, $\mathrm{PCr}$ /ATP ratios fell significantly in the uremic group ( $P<0.05$, two-tailed Mann-Whitney test), while there was no significant change in the $\mathrm{PCr} / \mathrm{ATP}$ ratios between the control groups (see control groups unstressed versus stressed in Figure $2 \mathrm{~A}$ and $\mathrm{B})$. However, there were significant reductions in $\mathrm{PCr} / \mathrm{ATP}$ ratios in the stressed hearts from uremic animals compared to those from SH-operated animals (Figure 2B).

\section{Eight-week stressed heart CZE study}

The hearts were freeze clamped following an intravenous infusion of dobutamine $\left(15 \mu \mathrm{g} \cdot \mathrm{kg}^{-1} \cdot \mathrm{min}^{-1}\right.$ for 20 minutes prior

Table 5 Eight-week CZE study in hearts

\begin{tabular}{llll}
\hline & Control & Uremic & $P$ \\
\hline Number of animals & 8 & 8 & \\
Mean arterial blood pressure $(\mathrm{mmHg})$ & $141 \pm 15$ & $174 \pm 22$ & $<0.0 \mathrm{I}$ \\
Hemoglobin $(\mathrm{g} / \mathrm{dL})$ & $15.0 \pm 2.7$ & $11.3 \pm 3.2$ & 0.03 \\
Creatinine $(\mu \mathrm{mol} / \mathrm{L})$ & $45.5 \pm 10.0$ & $189.8 \pm 80.2$ & $<0.0 \mathrm{I}$ \\
Heart wet $\mathrm{wt} / \mathrm{dry}$ wt ratio & $24.3 \% \pm 2.2 \%$ & $26.7 \% \pm 5.9 \%$ & $\mathrm{NS}$ \\
$\mathrm{PCr}(\mathrm{nmol} / \mathrm{mg}$ heart tissue) & $13.8 \pm 6.1$ & $14.0 \pm 1.78$ & $\mathrm{NS}$ \\
ATP $(\mathrm{nmol} / \mathrm{mg}$ heart tissue) & $12.0 \pm 2.1$ & $13.1 \pm 3.2$ & $\mathrm{NS}$ \\
ADP $(\mathrm{nmol} / \mathrm{mg}$ heart tissue) & $7.94 \pm \mathrm{I} .14$ & $7.80 \pm 2.36$ & $\mathrm{NS}$ \\
AMP $(\mathrm{nmol} / \mathrm{mg}$ heart tissue) & $3.15 \pm \mathrm{I} .55$ & $2.5 \mathrm{I} \pm 1.30$ & $\mathrm{NS}$ \\
\hline
\end{tabular}

Notes: CZE measurements using unstressed hearts at 8 weeks showing baseline animal data and the concentrations of high-energy phosphate-containing molecules. Values given are mean $\pm S D$, and statistical analysis was performed by unpaired Student's t-test.

Abbreviations: CZE, capillary zone electrophoresis; wt, weight; NS, not significant; PCr, phosphocreatine; ATP, adenosine triphosphate; ADP, adenosine diphosphate; AMP, adenosine monophosphate.
Table 6 Eight-week stressed heart NMR study

\begin{tabular}{llll}
\hline & Control & Uremic & $P$ \\
\hline Number of animals & 5 & 5 & \\
Animal weight $(\mathrm{g})$ & $442 \pm 55$ & $409 \pm 4 \mathrm{I}$ & $\mathrm{NS}$ \\
Mean arterial blood pressure $(\mathrm{mmHg})$ & $108 \pm 6$ & $152 \pm 32$ & 0.02 \\
Hemoglobin $(\mathrm{g} / \mathrm{dL})$ & $12.5 \pm 0.7$ & $10.1 \pm 2.0$ & 0.03 \\
Urea $(\mathrm{mmol} / \mathrm{L})$ & $6.4 \pm 0.7$ & $16.7 \pm 8.0$ & 0.04 \\
Creatinine $(\mu \mathrm{mol} / \mathrm{L})$ & $61 \pm 2$ & $154 \pm 89$ & 0.04 \\
\hline
\end{tabular}

Notes: In vivo heart stress NMR experiments showing post-dobutamine animal data. Values given are mean $\pm S D$, and statistical analysis was performed by unpaired Student's t-test.

Abbreviations: NMR, nuclear magnetic resonance; NS, not significant.

to freeze clamping). Experiments were conducted 8 weeks following PNx (Table 7). While a comparison of ATP and $\mathrm{PCr}$ concentrations did not reach statistical significance, $\mathrm{PCr} /$ ATP ratios were significantly reduced in the uremic group compared to those in control animals $(P<0.05$, two-tailed Mann-Whitney test, Figure 2C).

\section{Discussion}

These experiments have demonstrated a reduction in the $\mathrm{PCr} /$ ATP ratio in uremic rat hearts in vivo 4 weeks after PNx. However, identical experiments conducted 8 weeks following PNx showed no reduction in the PCr/ATP ratio. A possible reason for this finding is that the development of adaptive and compensatory myocardial changes formed over time is masking bioenergetic abnormalities at rest. This hypothesis is supported by the evidence that the stressor agent dobutamine was able to reveal changes in the PCr/ATP at 8 weeks that were not seen when the hearts were unstressed (comparing Figure 2A and B). Tellingly, similar bioenergetic changes were observed when studying skeletal muscle, and this raises

Table 7 Eight-week stressed heart CZE study

\begin{tabular}{llll}
\hline & Control & Uremic & $P$ \\
\hline Number of animals & 7 & 9 & \\
Animal weight $(\mathrm{g})$ & $405 \pm 63$ & $383 \pm 59$ & $\mathrm{NS}$ \\
Mean arterial blood pressure $(\mathrm{mmHg})$ & $\mathrm{III} \pm 6$ & $15 \mathrm{I} \pm 26$ & $<0.0 \mathrm{I}$ \\
Hemoglobin $(\mathrm{g} / \mathrm{dL})$ & $12.6 \pm \mathrm{I} .2$ & $9.2 \pm 2.9$ & $0.0 \mathrm{I}$ \\
Urea $(\mathrm{mmol} / \mathrm{L})$ & $6.5 \pm 0.7$ & $15.5 \pm 5.5$ & $<0.0 \mathrm{I}$ \\
Creatinine $(\mu \mathrm{mol} / \mathrm{L})$ & $63.1 \pm 2.7$ & $138.2 \pm 58.8$ & $<0.0 \mathrm{I}$ \\
Heart wet wt/dry wt ratio & $21.2 \% \pm 3.2 \%$ & $23.8 \% \pm 4.1 \%$ & $\mathrm{NS}$ \\
PCr $(\mathrm{nmol} / \mathrm{mg}$ heart tissue) & $13.8 \pm 7.5$ & $12.6 \pm 4.5$ & $\mathrm{NS}$ \\
ATP $(\mathrm{nmol} / \mathrm{mg}$ heart tissue) & $19.8 \pm 6.2$ & $25.8 \pm 7.1$ & $\mathrm{NS}$ \\
ADP $(\mathrm{nmol} / \mathrm{mg}$ heart tissue) & $6.6 \pm 2.2$ & $6.4 \pm \mathrm{I} .8$ & $\mathrm{NS}$ \\
AMP $(\mathrm{nmol} / \mathrm{mg}$ heart tissue) & $2.7 \pm \mathrm{I} .8$ & $1.4 \pm 0.6$ & $\mathrm{NS}$ \\
\hline Notes CZE exp
\end{tabular}

Notes: CZE experiments using stressed hearts at 8 weeks showing baseline animal data and concentrations of high-energy phosphate-containing molecules. Values given are mean $\pm S D$, and statistical analysis is performed by unpaired Student's t-test.

Abbreviations: CZE, capillary zone electrophoresis; wt, weight; NS, not significant; PCr, phosphocreatine; ATP, adenosine triphosphate; ADP, adenosine diphosphate; AMP, adenosine monophosphate. 

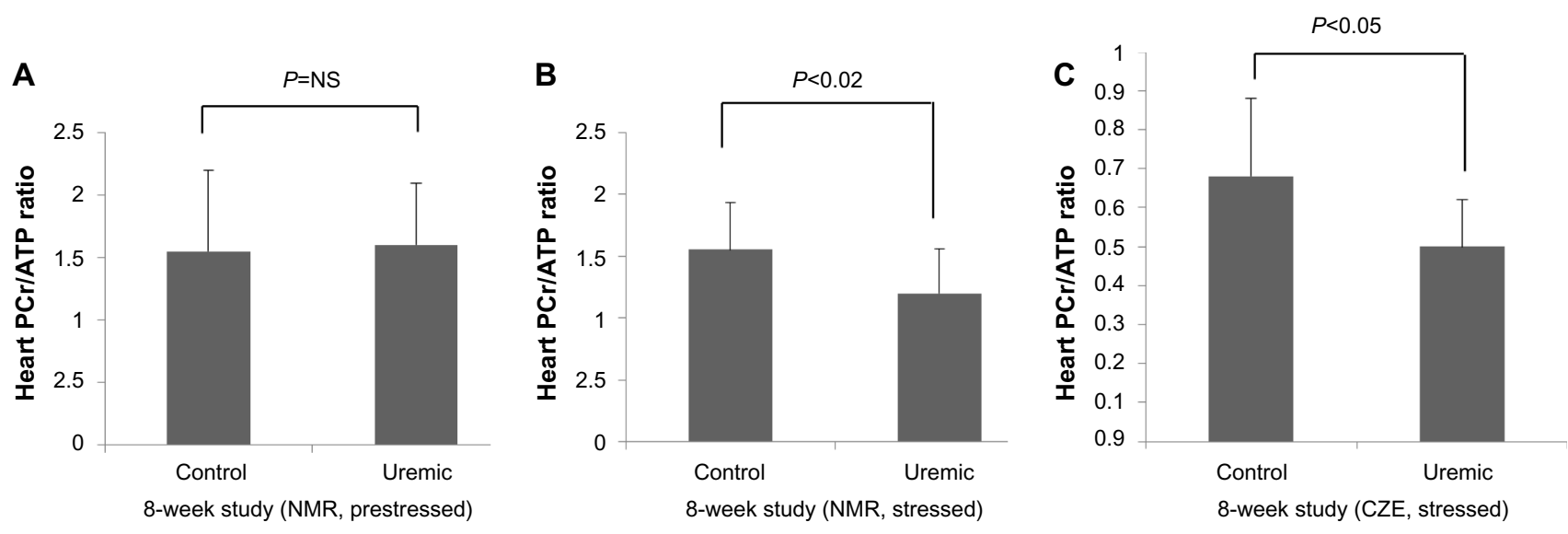

Figure $2 \mathrm{PCr} / \mathrm{ATP}$ ratios 8 weeks post-PNx in rats with dobutamine stress $\left(15 \mu \mathrm{g} \cdot \mathrm{kg}^{-1} \cdot \mathrm{min}^{-1}\right.$ for 20 minutes prior to freeze clamping).

Notes: Prior to dobutamine addition, as in the unstressed study, no significant difference in the PCr/ATP ratio was seen (A). However, dobutamine stress showed significant reductions in PCr/ATP ratios in the heart from uremic animals compared to sham-operated animals by both NMR (B) and CZE (C) determinations. Two-tailed Mann-Whitney analysis with median values \pm SD is presented.

Abbreviations: PCr, phosphocreatine; ATP, adenosine triphosphate; PNx, partial nephrectomy; NMR, nuclear magnetic resonance; CZE, capillary zone electrophoresis.

the possibility of using skeletal muscle bioenergetics as a surrogate tissue for the heart, as determination of skeletal muscle bioenergetics is a much easier and less invasive procedure to perform than cardiac measurement.

To the best of our knowledge, there are no reports in the literature of in vivo studies of myocardial bioenergetics measured by NMR in animal models of uremia at different time points or in the presence and absence of dobutamineinduced stress. However, Seymour's group in a study of myocardial substrate utilization using an in vivo uremic model have determined altered cardiac bioenergetics, but only at a single time point. ${ }^{23,24}$ Interesting recent work from the same group has revealed how mitochondrial respiration in the uremic heart is chronically uncoupled. ${ }^{25}$ Raine et al ${ }^{18}$ studied the hearts of rats 3 weeks following PNx using an isolated working heart model. Here they demonstrated reduced $\mathrm{PCr} /$ ATP ratios, similar in pattern to the results obtained in these experiments 4 weeks post-PNx in vivo.

There are many possible causes for a diminished $\mathrm{PCr} /$ ATP ratio in the heart. In normal circumstances, large changes in energy expenditure produce only modest changes in the PCr/ATP ratio as a result of the tight regulation of oxidative phosphorylation. ${ }^{26}$ Oxygen limitation due to cell metabolism may occur because of the well-recognized capillary rarefaction. Anemia may exacerbate this effect, in addition to any increase in catecholamine levels or myocyte sensitivity to catecholamines ${ }^{5,27,28}$ with or without changes in intracellular changes in calcium concentration and sensitivity. Catecholamine stress has also been shown to reduce the PCr/ATP ratio in obese subjects but not in subjects of normal weight. ${ }^{5}$
Another possible cause of abnormal myocardial bioenergetics in uremia may be due to altered substrate utilization. Previous studies in animals have shown that in LVH, an increase in the utilization of glucose in preference to free fatty acids occurs. ${ }^{29}$ Christe and Rodgers studied the isolated perfused heart of the spontaneously hypertensive rat with LVH and hypertension. ${ }^{30}$ They found enhanced glucose oxidation and suppressed fatty acid oxidation in the spontaneously hypertensive rat compared to normotensive controls. Similar findings of depressed fatty acid oxidation ${ }^{31,32}$ and enhanced glycolytic capacity ${ }^{33}$ have been observed in other forms of LVH. It is possible that in the uremic environment, the substrate specificity is different from normal hearts early on during the course of uremia, and this may explain the decreased $\mathrm{PCr} / \mathrm{ATP}$ ratio seen at 4 weeks post-PNx. The change in substrate utilization may take some time to become fully effective, and this is a possible explanation for the "normalization" of PCr/ATP ratios seen in the uremic hearts at 8 weeks: the adaptive mechanism has become functional.

A loss of total creatine in the heart, as seen in some nonuremic models of $\mathrm{LVH},{ }^{34}$ might also lead to a reduction in $\mathrm{PCr}$ concentration and a reduction in $\mathrm{PCr} / \mathrm{ATP}$ ratio via the creatine kinase system. Total creatine was not measured in these experiments, but it is noteworthy that Raine et al ${ }^{18}$ did not find any reduction in total creatine in the uremic heart despite finding significant reductions in $\mathrm{PCr} / \mathrm{ATP}$ ratios in the isolated perfused heart. Reduced total creatine therefore appears unlikely to be the cause of the abnormalities seen in the uremic heart.

Uremic skeletal muscle showed similar bioenergetic changes as cardiac tissue. Uremic animal skeletal muscle was studied 4 weeks after PNx and found to have reduced 
PCr/ATP ratios compared to control skeletal muscle. Rats studied 8 weeks post-PNx had no difference in their muscle $\mathrm{PCr} / \mathrm{ATP}$ ratios when compared to $\mathrm{SH}$-operated control animals. These findings therefore closely mirror the cardiac data. Previous studies of skeletal muscle bioenergetics in uremia have produced conflicting results. One study of calf muscle in dialysis patients using NMR found no differences in PCr, ATP, or inorganic phosphate levels at rest, but when the muscle was exercised, a reduction in PCr and ATP concentrations was seen in uremic patients. ${ }^{35}$ Recovery of $\mathrm{PCr}$ concentrations was slower in the dialysis group, suggesting a defect in oxidative metabolism in the uremic muscle. ${ }^{35}$ Another study provides support for this conclusion, with a decreased calculated phosphorylation potential in the skeletal muscle of dialysis patients compared to healthy control subjects. ${ }^{36}$

The results described here suggest that skeletal muscle and cardiac muscle may behave in a similar manner in CKD. Skeletal muscle is simpler to study in vivo than cardiac muscle, and results obtained in skeletal muscle may therefore prove to extend to cardiac muscle. Moreover, intracellular $\mathrm{pH}$ in skeletal muscle can be measured much more easily than in cardiac muscle. Skeletal muscle intracellular $\mathrm{pH}$ in uremic and control groups was found to be similar, consistent with other published findings, ${ }^{35}$ which permits us to rule out acid/base changes being the cause of the abnormal bioenergetics.

The work presented here is not without its limitations. More definitive evidence would have been provided in terms of bioenergetics reserve if we had conducted dobutamine stress in the heart tissue at 4 weeks and further confirmation of the surrogate nature of skeletal muscle had we performed a stress test in that tissue at 8 weeks. However, this was only appreciated after the study was complete. Nevertheless, we believe that the evidence shown here in this in vivo study provides important data of bioenergetics in a realistic setting of uremia, with no restriction of substrate or neurohumoral mechanisms such as those found in ex vivo studies. In addition, our in vivo NMR data are supported by our chromatographic study using CZE. This suggests that the changes in bioenergetics measured by NMR in this study do reflect genuine changes in high-energy phosphates in vivo and furthermore give credence to the possibility of using skeletal muscle as a useful surrogate marker for cardiac tissue in clinical subjects where required.

\section{Conclusion}

This study provides evidence of the impaired myocardial bioenergetics in experimental uremia and that skeletal muscle bioenergetics changes mirror those seen in the cardiac tissue. Therefore, skeletal muscle could potentially be used as a surrogate tissue during clinical cardiac NMR studies. This work has also highlighted the utility of catecholaminergic stress induced by dobutamine being able to unmask the changes in energetics that had resulted from experimental uremia.

\section{Acknowledgments}

The authors would like to acknowledge the help given by Dr Anne-Marie Seymour in initiating this project. AMSC was supported by a British Heart Foundation's Junior Fellowship grant during this study.

\section{Disclosure}

The authors report no conflicts of interest in this work.

\section{References}

1. Siedlecki AM, Jin X, Muslin AJ. Uremic cardiac hypertrophy is reversed by rapamycin but not by lowering of blood pressure. Kidney Int. 2009;75:800-808.

2. Semple D, Smith K, Bhandari S, Seymour AM. Uremic cardiomyopathy and insulin resistance: a critical role for Akt? J Am Soc Nephrol. 2010;21:207-215.

3. Horowitz JD, Chirkov YY, Kennedy JA, Sverdlov AL. Modulation of myocardial metabolism; an emerging therapeutic principle. Curr Opin Cardiol. 2010;25:329-334.

4. Jameel MN, Zhang J. Myocardial energetics in left ventricular hypertrophy. Curr Cardiol Rev. 2009;5:243-250.

5. Rider OJ, Francis JM, Ali MK, et al. Effects of catecholamine stress on diastolic function and myocardial energetics in obesity. Circulation. 2012;125:1511-1519.

6. Scheuermann-Freestone M, Madsen PL, Manners D, et al. Abnormal cardiac and skeletal muscle metabolism in patients with type 2 diabetes. Circulation. 2003;107:3040-3046.

7. Shivu GN, Abozguia K, Phan TT, Ahmed I, Henning A, Frenneaux M. ${ }^{31} \mathrm{P}$ magnetic resonance spectroscopy to measure in vivo cardiac energetics in normal and hypertrophic cardiomyopathy: experiences with 3T. Eur J Radiol. 2010;73:255-259.

8. Masuda Y, Tateno Y, Ikehira H, et al. High-energy phosphate metabolism of the myocardium in normal subjects and patients with various cardiomyopathies - the study using ECG gated MR spectroscopy with a localization technique. Jpn Circ J. 1992;56:620-626.

9. Schaefer S, Gober JR, Schwartz GG, Twieg DB, Weiner MW, Massie B. In vivo phosphorus -31 spectroscopic imaging in patients with global myocardial disease. Am J Cardiol. 1990;65:1154-1161.

10. Conway MA, Akis J, Ouwerkerk R, Niioka T, Rajagopalan B, Radda GK. Detection of low phosphocreatinine in ATP ratio in failing hypertrophied human myocardium by ${ }^{31} \mathrm{P}$ magnetic resonance spectroscopy. Lancet. 1991;338:973-976.

11. Neubauer S, Horn M, Cramer M, et al. Myocardial phosphocreatinineto-ATP ratio is a predictor of mortality in patients with distal cardiomyopathy. Circulation. 1997;96:2190-2196.

12. Conway MA, Bottomley PA, Ouwerkerk R, Radda GK, Rajagopalan B. Mitrial regurgitation: impaired systolic function, eccentric hypertrophy, and increased severity are linked to lower phosphocreatine/ATP ratios in humans. Circulation. 1998;97:1716-1723.

13. Lamb HJ, Beyerbacht HP, van der Laarse A, et al. Diastolic dysfunction in hypertensive heart disease as associated with altered myocardial metabolism. Circulation. 1999;99:2261-2267. 
14. Pluim BM, Lamb HJ, Kayser HW, et al. Functional and metabolic evaluations of the athlete's heart by magnetic resonance imaging and dobutamine stress magnetic resonance spectroscopy. Circulation. 1998;97:666-672.

15. Tagami T, Sakuma H, Matsumura K, et al. Evaluation of altered myocardial high energy phosphate metabolism in patients on maintenance dialysis using phosphorus-31 magnetic resonance spectroscopy. Invest Radiol. 1998;33:171-176.

16. Perseghin G, Fiorina P, De Cobelli F, et al. Cross-sectional assessment of the effect of kidney and kidney-pancreas transplantation on resting left ventricular energy metabolism in type 1 diabetic-uremic patients: a phosphorus-31 magnetic resonance spectroscopy study. J Am Coll Cardiol. 2005;46:1085-1092.

17. Patel RK, Mark PB, Macnaught G, et al. Altered relative concentrations of high-energy phosphates in patients with uraemic cardiomyopathy measured by magnetic resonance spectroscopy. Nephrol Dial Transplant. 2012;27:2446-2451.

18. Raine AE, Seymour AM, Roberts AF, Radda GK, Ledingham JG. Impairment of cardiac function and energetics in experimental renal failure. J Clin Invest. 1993;92:2934-2940.

19. McMahon AC, Vescovo G, Dalla Libera L, et al. Contractile dysfunction of isolated ventricular myocytes in experimental uraemia. Exp Nephrol. 1996;4:144-150.

20. Beech JS, Williams SC, Iles RA, et al. Haemodynamic and metabolic effects in diabetic ketoacidosis in rats of treatment and sodium bicarbonate or a mixture of sodium bicarbonate and sodium carbonate. Diabetologia. 1995;38:889-898.

21. Carlucci F, Biagioli B, Maccherini M, et al. Myocardial ischemic injury and purine metabolism in patients undergoing coronary artery bypass. Clin Biochem. 1998;31:235-239.

22. Grune T, Ross GA, Schmidt H, Siems W, Perrett D. Optimized separation of purine bases and nucleotides in human cord plasma by capillary zone electrophoresis. J Chromatogr. 1993;636:105-111.

23. Reddy V, Bhandari S, Seymour AML. Myocardial function, energy provision, and carnitine deficiency in experimental uremia. J Am Soc Nephrol. 2007;18:84-92.

24. Smith K, Semple D, Aksentijevic D, Bhandari S, Seymour AM. Functional and metabolic changes in uraemic cardiomyopathy. Front Biosci (Elite Ed). 2010;2:1492-1501
25. Taylor D, Bhanari S, Seymour AM. Mitochondrial dysfunction in uremic cardiomyopathy. Am J Physiol Renal Physiol. 2015;308:F579-F587.

26. Balaban RS. Regulation of oxidative phosphorylation in the mammalian cell. Am J Physiol Cell Physiol. 1990;258:C377-C389.

27. Brush JE Jr, Eisenhofer G, Garty M, et al. Cardiac norepinephrine kinetics in hypertrophic cardiomyopathy. Circulation. 1989;79:836-844.

28. Tarazi RC, Sen S, Saragoca M, Khairallah P. The multifactorial role of catecholamines in hypertensive cardiac hypertrophy. Eur Heart J. 1982;3:103-110.

29. Allard MF, Henning SL, Wambolt RB, Granleese SR, English DR, Lopaschuk GD. Glycogen metabolism in the aerobic hypertrophied rat heart. Circulation. 1997;96:676-682.

30. Christe ME, Rodgers RL. Altered glucose and fatty acid oxidation in hearts of the spontaneously hypertensive rat. J Mol Cell Cardiol. 1994;26:1371-1375.

31. Ben Cheikh R, Guendouz A, Moravec J. Control of oxidative metabolism in volume-overloaded rat hearts; effects of different lipid substrates. $\mathrm{Am}$ J Physiol Heart Circ Physiol. 1994;266:H2090-H2097.

32. el Alaoui-Talibi Z, Landormy S, Loireau A, Moravec J. Fatty acid oxidation and mechanical performance of volume-overloaded rat hearts. Am J Physiol Heart Circ Physiol. 1992;262:H1068-H1074.

33. Seymour AM, Eldar H, Radda GK. Hyperthyroidism results in increased glycolytic capacity in the rat heart. A ${ }^{31} \mathrm{P}-\mathrm{NMR}$ study. Biochim Biophys Acta. 1990;1055:107-116.

34. Wexler LF, Lorell BH, Momomura S, Weinberg EO, Ingwall JS, Apstein CS. Enhanced sensitivity to hypoxia-induced diastolic dysfunction in pressure-overload left ventricular hypertrophy in the rat: role of high energy phosphate depletion. Circ Res. 1988;62:766-775.

35. Durozard D, Pimmel P, Baretto S, et al. ${ }^{31} \mathrm{P}$ NMR spectroscopy investigation of muscle metabolism in hemodialysis patients. Kidney Int. 1993;43:885-892.

36. Thompson CH, Kemp GJ, Taylor DJ, Ledingham JG, Radda GK, Rajagopalan B. Effects of chronic uraemia on skeletal muscle metabolism in man. Nephrol Dial Transplant. 1993;8:218-222.

\section{Publish your work in this journal}

The International Journal of Nephrology and Renovascular Disease is an international, peer-reviewed open-access journal focusing on the pathophysiology of the kidney and vascular supply. Epidemiology, screening, diagnosis, and treatment interventions are covered as well as basic science, biochemical and immunological studies. The journal welcomes

\section{Dovepress}

original research, clinical studies, reviews \& evaluations, expert opinion and commentary, case reports and extended reports. The manuscript management system is completely online and includes a very quick and fair peerreview system, which is all easy to use. Visit http://www.dovepress.com/ testimonials.php to read real quotes from published authors 